\title{
全球变暖 $2^{\circ} \mathrm{C}$ 情景下中国平均气候和极端气候事件 变化预估
}

\author{
郎咸梅 ${ }^{*}$, 隋月 (2)(4) \\ (1) 中国科学院大气物理研究所, 国际气候与环境科学中心, 北京 100029 ; \\ (2) 中国科学院大气物理研究所, 竺可桢-南森国际研究中心, 北京 100029; \\ (3) 中国科学院东亚区域气候-环境重点实验室, 北京 100029; \\ (4) 中国科学院大学, 北京 100049 \\ * 联系人, E-mail: langxm@mail.iap.ac.cn
}

2012-07-01 收稿, 2012-09-12 接受, 2013-02-20 网络版发表

国家重点基础研究发展计划(2012CB955401)和国家自然科学基金(41175072)资助

\begin{abstract}
摘要 使用一个区域气候模式(RegCM3)在 IPCC SRES A1B 温室气体排放情景下对东亚地区 进行的高分辨率数值模拟试验数据, 就备受关注的相对于工业化革命前期全球变暖 $2^{\circ} \mathrm{C}$ 阈值 情景下中国平均气候和极端气候事件变化进行了预估研究. 结果表明, 届时中国年平均温度 普遍上升而且幅度要高于同期全球平均值约 $0.6^{\circ} \mathrm{C}$, 增温总体上由南向北加强并在青藏高原 地区有所放大, 各季节变暖幅度相似但空间分布有一定差别; 年平均降水相对于 1986 2005 年平均增加 $5.2 \%$, 季节降水增加 $4.2 \%$ 8.5\%, 除冬季降水在北方增加而在南方减少之外, 年 和其他季节平均降水主要表现为在中国西部和东南部增加而在两区域之间减少. 极端暖性温 度事件普遍增加, 而极端冷性温度事件减少; 中国区域年平均的连续 5 天最大降水量、降水 强度、极端降水贡献率和大雨日数分别增加 $5.1 \mathrm{~mm}, 0.28 \mathrm{~mm} \mathrm{~d}^{-1}, 6.6 \%$ 和 $0.4 \mathrm{~d}$, 而持续千期减 少 $0.5 \mathrm{~d}$, 其中大雨日数和持续千期变化存在较大的空间变率.
\end{abstract}

\section{关键词}

全球变暖

$2{ }^{\circ} \mathrm{C}$ 阈值

区域气候模式 中国平均气候 极端气候事件 预估
有关气候变化的观测研究表明, 工业化革命以 来随着人为温室气体和气溶胶排放以及土地利用变 化, 全球和中国平均温度上升, 并连同其他气候要素 和极端天气和气候事件变化一起日益影响世界和区 域环境、经济以及人们的日常生活, 气候变化事实和 归因以及预估研究已经成为地学领域的前沿课题, 并被社会各界所广泛关注 ${ }^{[1,2]}$. 为科学适应、减缓和应 对气候变化, 需要根据现有认知水平就未来全球和 中国气候变化进行有效的预估研究, 以便为国家制 定有关气候变化决策提供依据.

根据气候变化的生物地球化学影响、脆弱性分析 和风险性评估综合研究, 全球变暖 $2^{\circ} \mathrm{C}$ 阈值概念被提
出，并已被包括欧盟成员国在内的一百多个国家和 许多国际组织所接受和支持 ${ }^{[3,4]}$. 它的主要观点是: 相对于工业化革命前期全球平均温度上升 $2^{\circ} \mathrm{C}$ 是一 个阈值, 届时气候变化将会导致气候系统各个圈层, 尤其是与人类活动密切相关的淡水资源、粮食产量、 海平面上升、海洋酸化、生物多样性、极端天气和气 候事件等方面发生不可逆的或者灾难性的变化, 并 将最终威胁到人类的生存环境 ${ }^{[3,5]}$. 尽管在科学层面 上还有不同意见，但避免 $2^{\circ} \mathrm{C}$ 全球变暖已经成为国际 上有关气候变化谈判和制定温室气体减排目标的主 要依据 ${ }^{[4,6 \sim 10]}$, 相应的气候变化预估工作在国际上也 越来越受到重视, 其中主要包括 $2^{\circ} \mathrm{C}$ 全球变暖何时发 $012-5520-5$ 
生 ${ }^{[11]}$ 以及发生之后全球和区域尺度气候、植被、极 端天气和气候事件如何变化 ${ }^{[12 ~ 16]}$.

近些年来, 中国学者已在全球和东亚气候变化 方面开展了大量预估工作 ${ }^{[2,17,18]}$, 但有关阈值或者关 键值的研究却十分有限. 先前, 国际耦合模式比较计 划第 3 阶段(CMIP3)中 17 个气候模式的试验结果曾被 用来研究相对于 1990 1999 年, 21 世纪中国区域 $1 \sim 3^{\circ} \mathrm{C}$ 变暖关键值的时空分布特征 ${ }^{[19]}$, 但它与 $2^{\circ} \mathrm{C}$ 全 球变暖分属不同的问题. 近期, 有科研人员根据 CMIP3 中 16 个气候模式结果研究了相对于工业化革 命前期, $2^{\circ} \mathrm{C}$ 全球变暖发生时间以及与之相对应的大 气中主要温室气体浓度和中国气候状况 ${ }^{[20]}$. 然而, 就区域气候变化而言, 全球气候模式的水平分辨率 相对较低, 需要进行降尺度研究, 特别是考虑到高分 辨率区域气候模式对于中国降水有更好的模拟能

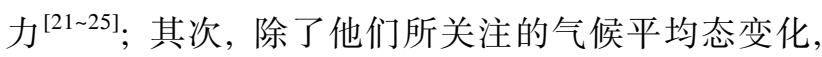
事实上极端气候事件变化的影响更为关键, 迫切需 要系统评估以填补这方面信息的空白. 为此, 本文根 据一个高分辨率区域气候模式对东亚气候的长时间 连续积分试验, 就 $2^{\circ} \mathrm{C}$ 全球变暖情景下中国平均气候 和极端气候事件进行了综合预估研究, 旨在揭示该 阈值对于中国气候究竟意味着什么.

\section{1 资料与分析方法}

本文所用数据为意大利国际理论物理中心的区

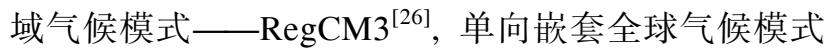
MIROC3.2_hires 输出结果, 在 A1B 温室气体和气溶 胶排放情景下对中国及东亚地区进行的高分辨率数 值试验资料 ${ }^{[27 ~ 29]}$. 其中, MIROC3.2_hires 大气部分水 平分辨率为 $\mathrm{T} 106$, 相当于 $125 \mathrm{~km}$, 它是 CMIP3 中水 平分辨率最高的模式, 对东亚气候有较好的模拟能 力 $^{[30] ;}$ RegCM3 水平分辨率为 $25 \mathrm{~km}$, 垂直方向分 18 层, 模式顶层为 $10 \mathrm{hPa}$; 试验从 1948 年 1 月 1 日连续 积分到 2100 年 12 月 31 日, 共计 153 年, 其中 1948 1950 年是模式初始化阶段. 这是迄今为止区域气候模 式在东亚地区所进行的水平分辨率最高的 21 世纪气 候模拟试验, 而且模式性能评估表明 $\mathrm{RegCM} 3$ 对 1981 2000 年当代中国温度和降水具备较好的模拟能 力, 特别是对夏季降水型的模拟与观测基本吻合 ${ }^{[28]}$.

为了客观确定 $2^{\circ} \mathrm{C}$ 全球变暖发生年份及其所对应 的中国气候状况, 首先将 A1B 情景下 MIROC3.2_hires 所模拟的 2001 2100 年全球平均温度序列进行 $9 \mathrm{a}$ 滑
动平均处理, 以便有效消除年际尺度温度变率的影 响. 而后, 既然全球变暖 $2^{\circ} \mathrm{C}$ 阈值是相对于工业化革 命前期温度平均值而言的, 那么所选取的参考气候 时段原则上不应该受到 20 世纪气候变化的影响. 然 而, 为 $\mathrm{RegCM} 3$ 提供初边值条件的全球气候模式 MIROC3.2_hires 的 20 世纪气候模拟试验积分时段为 1900 2000 年, 并不包含工业化革命前期, 当然这也 是 CMIP3 中多数模式所存在的共性问题. 为此, 文 中根据国际上推荐的处理方法 ${ }^{[3]}$, 先选择 1990 2000 年作为参考时段, 之后据此对应查找 $1.4^{\circ} \mathrm{C}$ 全球变暖 发生年份, 因为该时段全球平均温度相比于工业化 革命前期的最优估计是变暖了 $0.6^{\circ} \mathrm{C}^{[1]}$. 由此确定, A1B 情景下 MIROC3.2_hires 试验中 $2^{\circ} \mathrm{C}$ 全球变暖发 生在 2029 年, 需要说明的是该年份相对于 CMIP3 同 一情景下其他模式的要更早一些 ${ }^{[20]}$, 这是因为 MIROC3.2_hires 中全球变暖的速度更快. 最终, 前 述 RegCM3 试验中的 2029 年及其前后各 4 年, 即 $2025 \sim 2033$ 年被视为全球变暖 $2^{\circ} \mathrm{C}$ 阈值所对应的时段. 在下文中, 我们将集中研究 2025 2033 年平均气候减 去 1986 2005 年平均气候的结果, 此处选择 1986 2005 年作为当代的原因在于它是政府间气候 变化专门委员会第五次评估报告为气候变化预估部 分而专门设定的参考时段.

\section{2 结果分析}

\section{$2.12^{\circ} \mathrm{C}$ 全球变暖情景下中国平均气候变化预估}

如图 1 所示, 在 $2^{\circ} \mathrm{C}$ 全球变暖情景下, 中国年和 季节平均温度相对于 1986 2005 年显著变暖. 总的来 说，在大尺度上年和季节平均温度上升表现为从南 向北加强, 青藏高原比它周边地区的升温要更大一 些, 事实上这与 20 世纪后半段观测的和全球气候模 式模拟的 21 世纪中国温度变化有相同的空间分布特 征 ${ }^{[2]}$. 除华南和西南局部外, 中国年平均温度升幅均 要大于 $1.4^{\circ} \mathrm{C}$ (图 1(a)), 区域平均值为 $2.0^{\circ} \mathrm{C}$, 这意味 着相对于工业化革命前期中国变暖 $2.6^{\circ} \mathrm{C}$ 左右, 比同 期全球变暖 $2^{\circ} \mathrm{C}$ 要更大, 这与先前 16 个全球气候模 式在 $\mathrm{A} 1 \mathrm{~B}$ 情景下得到的 $2.9^{\circ} \mathrm{C}^{[20]}$ 相一致, 但幅度相对 而言要小约 $0.3^{\circ} \mathrm{C}$. 在季节尺度上, 春、夏、秋、冬季 中国区域平均温度分别上升 $1.9,1.9,2.0$ 和 $2.0^{\circ} \mathrm{C}$, 幅 度与年平均 $2.0^{\circ} \mathrm{C}$ 相近或相同且彼此之间差别不大. 季节温度变化空间分布总体上也与年平均相似, 但 

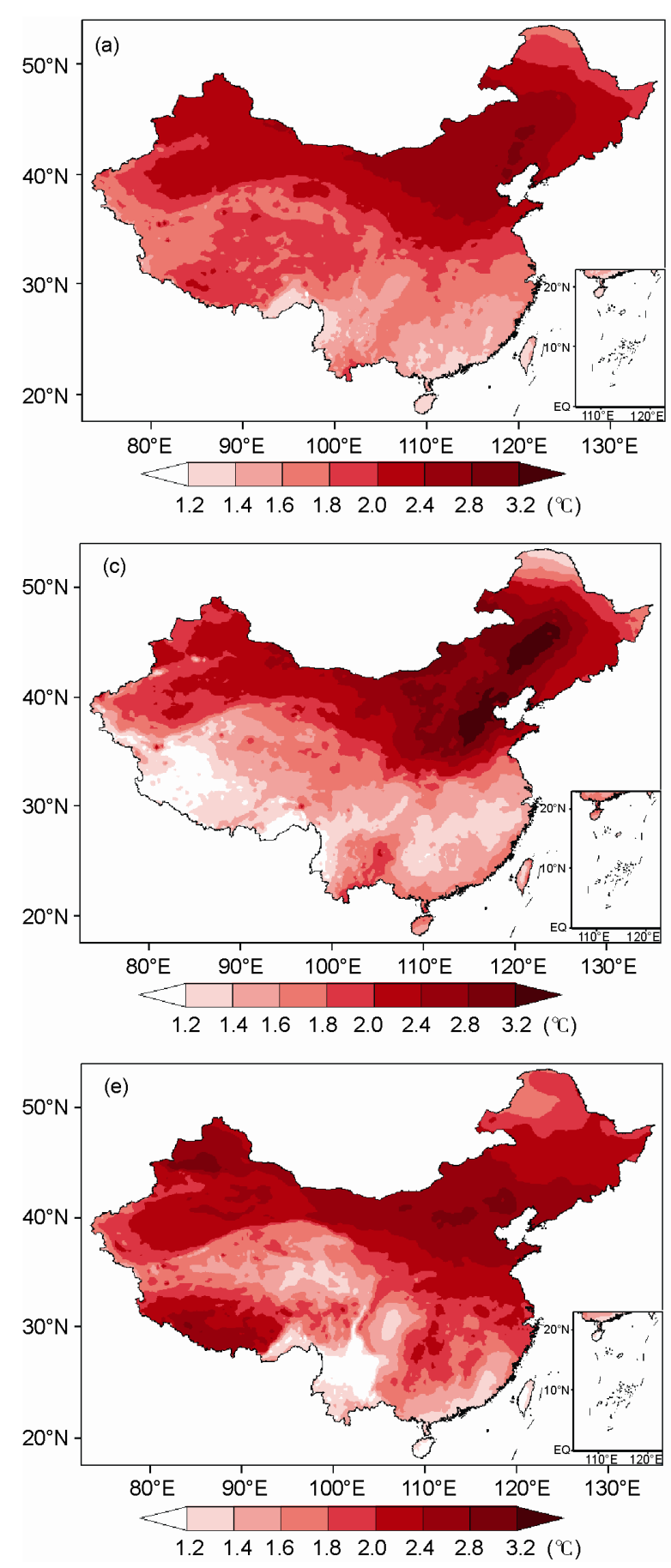

存在一定程度的差异 (图 1(b) (e)). 其中, 夏季在中 国北方特别是东北中部和南部和华北大部的升温更 大, 而在南方和青藏高原地区升温则偏小, 冬季在西 南地区则存在一个升温小值区, 值得注意的是这些 变化特征在 21 世纪中期和末期同样存在 ${ }^{[28]}$.

在 $2^{\circ} \mathrm{C}$ 全球变暖情景下, 中国区域年平均降水相 对于 1986 2005 年平均值增加了 5.2\%, 并表现出区
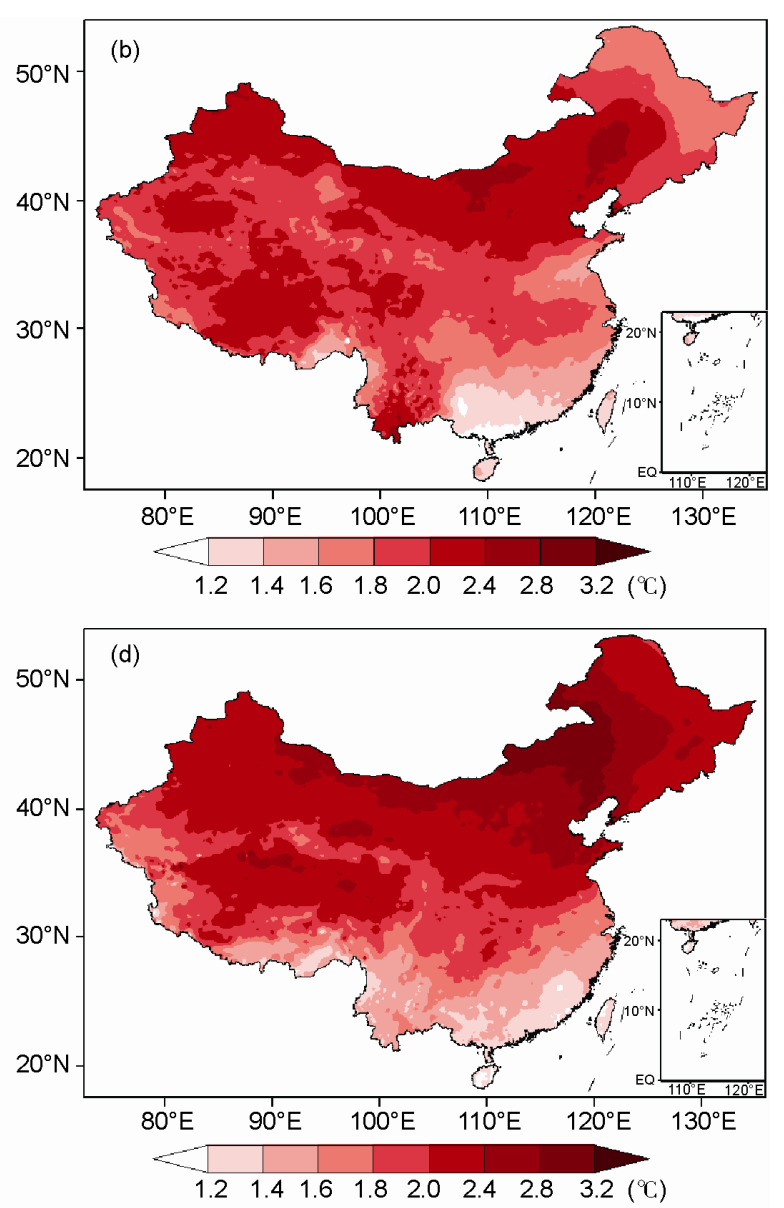

图 1 相对于 1986 2005 年当代气候, 在 2025 2033 年 ${ }^{\circ} \mathrm{C}$ 全球变暖情景下中国温度变化

(a) 年平均; (b) 春季; (c) 夏季; (d) 秋季; (e) 冬季

域间和季节性变化差异(图 2). 首先, 如图 2(a)所示, 年平均降水相对于 1986 2005 年主要表现为在约 $105^{\circ} \mathrm{E}$ 以西和中国东南部地区降水增加，而二者之间 则存在一条从西南至东北的降水减少带; 其中, 年降 水量变化幅度大多在 $25 \%$ 以内, 在塔里木盆地由于 当代的年降水量很小, 所以那里的降水百分比变化 相对于其他地区要偏大一些. 从季节尺度来看, 中国 

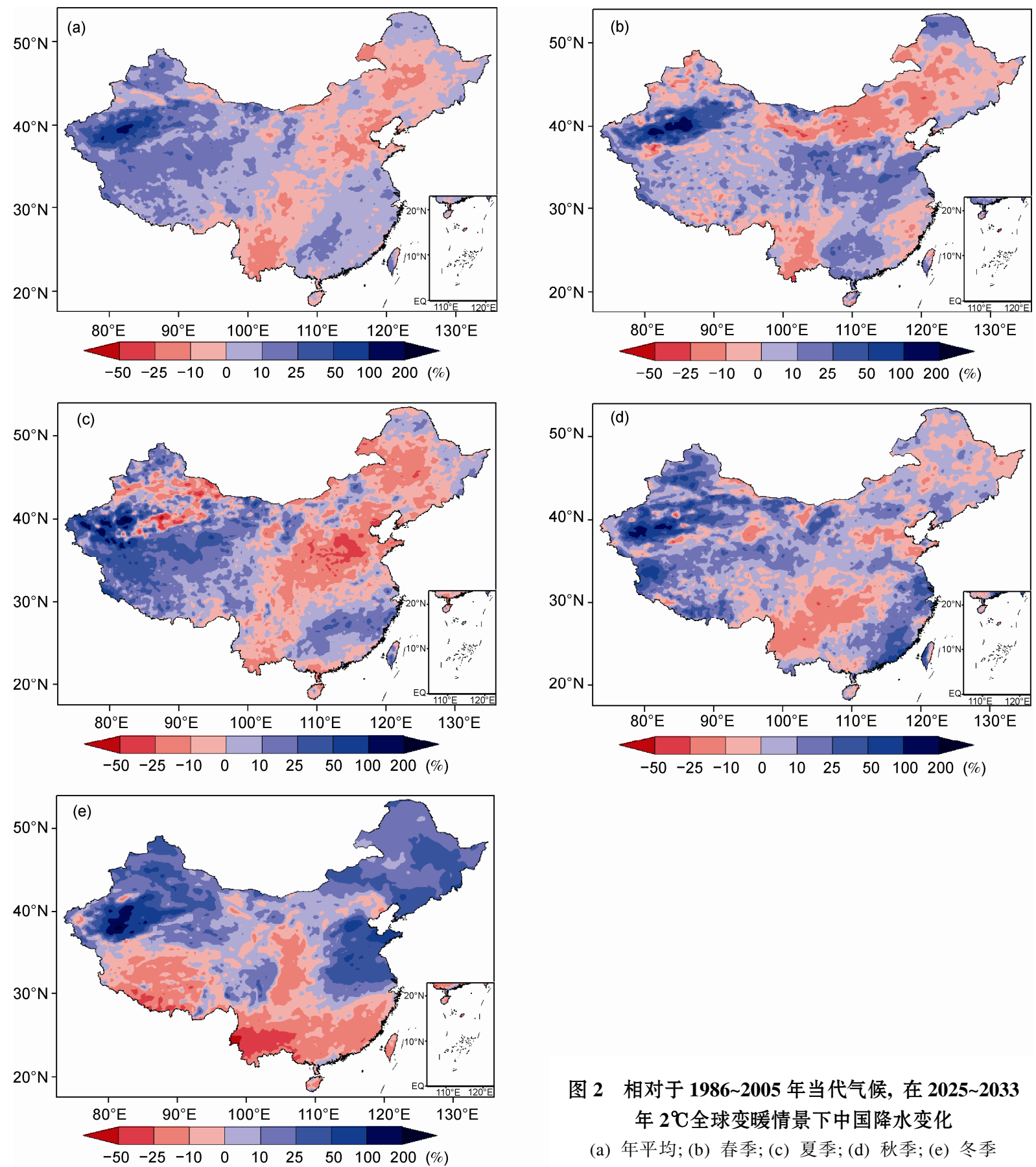

图 2 相对于 1986 2005 年当代气候, 在 2025 2033 年 ${ }^{\circ} \mathrm{C}$ 全球变暖情景下中国降水变化

(a) 年平均; (b) 春季; (c) 夏季; (d) 秋季; (e) 冬季

春、夏、秋、冬季降水与年平均一样整体上均表现为 增加趋势, 区域平均降水变化分别为 $4.7 \%, 4.2 \%$, $7.1 \%$ 和 $8.5 \%$. 由于中国降水, 特别是东部季风区降 水主要发生在夏季, 所以夏季降水在很大程度上决 定着年降水丰枯, 这就不难理解图 2(a)和(c)所示的 年和夏季降水变化在空间分布上存在着很大的一致 性. 另外, 不同于年平均降水变化, 春季长江和黄河 流域中下游地区降水增加(图 2(b))，秋季东北和华北 及其周边地区并未出现系统性的降水变化(图 2(d)). 在冬季, 降水变化主要表现为在北方增多而在南方 减少, 其中塔里木盆地和江淮流域降水增加较为明 显，多在 10\% 50\%之间，而青藏高原和华南地区降 水减少，幅度多为 10\% 50\%(图 2(e)). 值得进一步指 出的是, 在近年来时常发生严重干旱的包括云南在 
内的中国西南部地区, 无论是年平均还是季节平均 降水均减少, 这与 $\mathrm{RegCM} 3$ 模拟的 21 世纪中期和末 期降水变化相似 ${ }^{[28]}$.

相对于 1986 2005 年气候平均态, 在 $2{ }^{\circ} \mathrm{C}$ 全球变 暖情景下我们所关注的东亚季风环流也发生了变化. 夏季, $850 \mathrm{hPa}$ 风场异常主要表现为在中国东北中部 和东部以及环渤海地区盛行偏北风气流，季风环流 减弱, 而在约 $30^{\circ} \mathrm{N}$ 以南地区为偏南风气流, 季风环 流加强(图 3(a)). 前者是因为围绕着日本及其以东海 域出现了一个异常低压中心, 它导致西北太平洋暖 高压系统减弱, 在 $850 \mathrm{hPa}$ 上对应着一个气旋性环流 异常, 它西侧的偏北风气流引起了上述中国北方地 区季风环流的减弱. 另一方面, 由于中国东部内陆地 区变暖幅度要大于南海地区, 南北向海陆热力差异 相应加大, 进而引起华南地区出现偏南风气流异常.

冬季，欧亚大陆被冷高压所控制，而西北太平洋 上则为暖低压系统, 这种海陆间热力和气压差异使 得中国东部盛行偏北风气流(图 3(b)). 相对于 1986 2005 年气候态, 在 $2^{\circ} \mathrm{C}$ 全球变暖情景下中国东 部约 $35^{\circ} \mathrm{N}$ 以北地区在 $850 \mathrm{hPa}$ 上表现为偏南风气流 异常, 对应着冬季风环流减弱. 这是因为由于海洋和 大陆之间的热容量不同，在相同或者相似辐射强迫 条件下欧亚大陆东部中高纬度地区变暖速度要大于 西北太平洋地区，这就会引起中国东部沿岸地区原 有的大尺度东西向和西北至东南向海陆热力差异减 小 ${ }^{[31]}$, 海平面气压差或者梯度减小, 从而最终引起 西北风气流减弱。

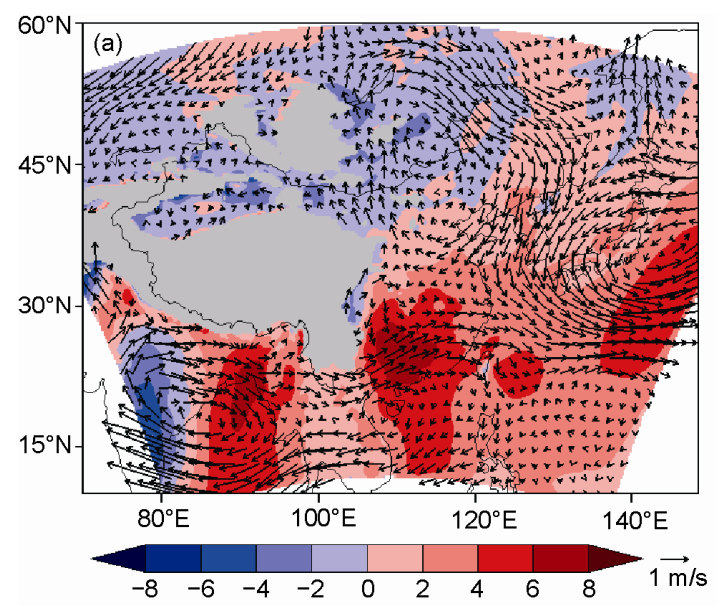

图 3 相对于 1986 2005 年当代气候, 在 2025 2033 年 $2^{\circ} \mathrm{C}$ 全球变暖情景下 $850 \mathrm{hPa}$ 风场变化 矢量箭头为风场变化, 填色区为当代 $850 \mathrm{hPa}$ 经向风气候态分布, 其中南风为正值. (a) 夏季; (b) 冬季

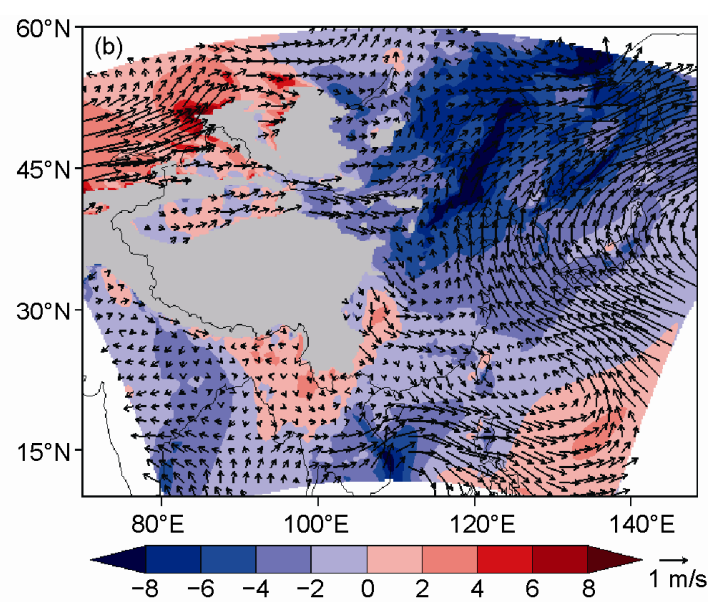

\section{$2.22^{\circ} \mathrm{C}$ 全球变暖情景下中国极端气候事件变化 预估}

本文选取了 10 个在国际气候学领域中常用的极 端温度和降水事件指标 ${ }^{[32]}$, 集中研究了 $2^{\circ} \mathrm{C}$ 全球变暖 情景下它们在中国区域的变化趋势. 其中, 极端温度 事件指标包括霜冻日数、温度年较差、生长季长度、 热浪指数和暖夜指数, 极端降水事件指标有大雨日 数、持续干期、连续 5 天最大降水量、降水强度和极 端降水贡献率, 有关它们的具体定义见表 1 .

相对于 1986 2005 年当代气候, 在 $2{ }^{\circ} \mathrm{C}$ 全球变暖 情景下除温度年较差之外的极端温度事件指标在中 国区域总体上均表现出了一致性变化趋势(图 4). 随 着温度平均值上升, 中国年平均霜冻日数平均减少 $17.0 \mathrm{~d}$, 其中华南局部和西藏西部地区减少 $0 \sim 10 \mathrm{~d}$, 中国北方大部分地区减少 10 20 d, 长江和黄河流域 下游和青藏高原中部和东部地区减少最为明显，平 均为 $20 \sim 30 \mathrm{~d}$. 温度年较差在新疆、内蒙古中部和西 部、西藏西部和南部边缘区、东北北部和长江中下游 局部地区减小，而在其余地区表现为增加，其中内蒙 古东部和西南地区增幅较大, 但上述变化幅度均在 $3^{\circ} \mathrm{C}$ 以内, 区域平均值为减小 $0.5^{\circ} \mathrm{C}$. 除在西藏西北侧 边缘区和华南沿岸局部以及海南以外, 生长季长度 在中国普遍增加, 其中在华南南部和东北北部以及 西藏北部小幅增加 0 10 d, 在西藏东南部增加 $20 \mathrm{~d}$ 以 上且局部地区要超过 $40 \mathrm{~d}$, 中国区域平均增加 $18.1 \mathrm{~d}$. 热浪指数在中国大部分地区以增加 $0 \sim 6 \mathrm{~d}$ 为主, 整个 区域的平均增加值为 $2.1 \mathrm{~d}$, 但在东北北部、华南沿 
表 1 极端气候事件指标的定义 ${ }^{\text {a) }}$

\begin{tabular}{lclc}
\hline \multicolumn{1}{c}{ 指标名称 } & 英文缩写 & \multicolumn{1}{c}{ 指标定义 } & 指标单位 \\
\hline 霜冻日数 & $\mathrm{FD}$ & 一年中日最低温度低于 $0^{\circ} \mathrm{C}$ 的总天数 & $\mathrm{d}$ \\
温度年较差 & $\mathrm{ETR}$ & 一年中日最高温度和日最低温度的差值 & ${ }^{\circ} \mathrm{C}$ \\
生长季长度 & $\mathrm{GSL}$ & 一年中日平均温度至少连续 6 天高于 $5{ }^{\circ} \mathrm{C}$ 的总天数 & $\mathrm{d}$ \\
热浪指数 & $\mathrm{HWDI}$ & 一年中至少连续 5 天最高温度高于气候态相同日期 $5{ }^{\circ} \mathrm{C}$ 的最长时段 & $\mathrm{d}$ \\
暖夜指数 & $\mathrm{Tn} 90$ & 一年中日最低温度通过 $90 \%$ 國值气候态分布的天数百分率 & $\%$ \\
大雨日数 & $\mathrm{R} 10$ & 一年中日降水量 $\geqslant 10 \mathrm{~mm}$ 的日数 & $\mathrm{d}$ \\
持续干期 & $\mathrm{CDD}$ & 一年中日降水量连续 $<1 \mathrm{~mm}$ 的最长时期 & $\mathrm{d}$ \\
连续 5 天最大降水量 & $\mathrm{R} 5 \mathrm{~d}$ & 一年中连续 $5 \mathrm{~d}$ 降水量之和的最大值 & $\mathrm{mm}$ \\
降水强度 & $\mathrm{SDII}$ & 年降水量与降水日数 $($ 日降水量 $\geqslant 1.0 \mathrm{~mm}$ )比值 & $\mathrm{mm} \mathrm{d}^{-1}$ \\
极端降水贡献率 & $\mathrm{R} 95 \mathrm{~T}$ & 一年中日降水量大于 $95 \%$ 分位数的降水量之和占年总降水量的百分比 & $\%$ \\
\hline
\end{tabular}

a) 根据文献[32]翻译
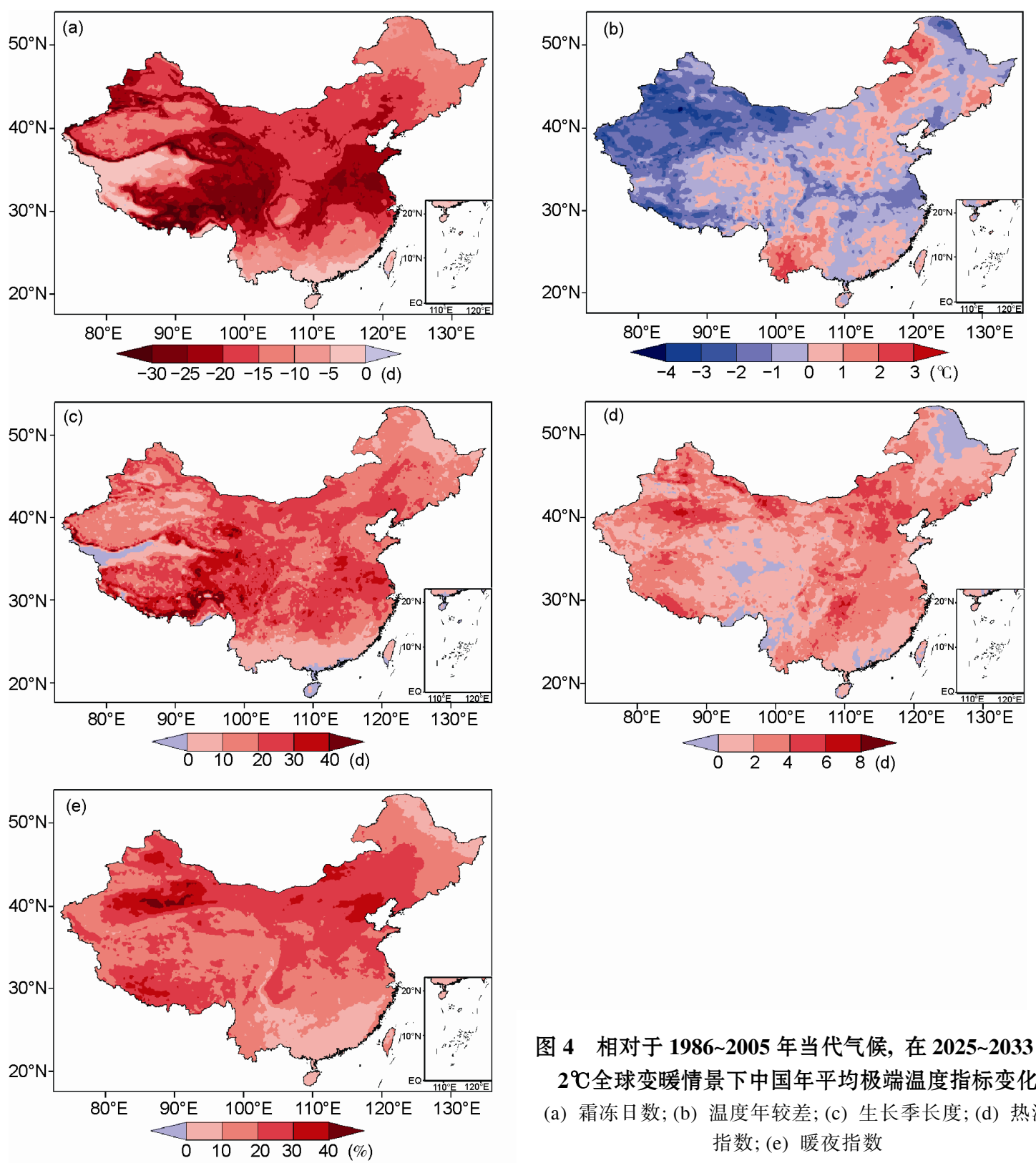

图 4 相对于 1986 2005 年当代气候, 在 2025 2033 年 $2{ }^{9} \mathrm{C}$ 全球变暖情景下中国年平均极端温度指标变化

(a) 霜冻日数; (b) 温度年较差; (c) 生长季长度; (d) 热浪 指数; (e) 暖夜指数 
岸、青藏高原东部以及西南的部分地区热浪指数则略 有减小. 暖夜指数在中国平均增加 $19.2 \%$, 其增幅在 华南和东北的北部边缘区相对较小，而在京津冀和 新疆中南部地区相对较大. 综上所述，中国区域暖性 极端温度事件指数增加, 而冷性极端温度事件减少, 这与 20 世纪后期全球变暖背景下观测的中国极端温 度事件指数变化 ${ }^{[18,33]}$ 具有很好的一致性.
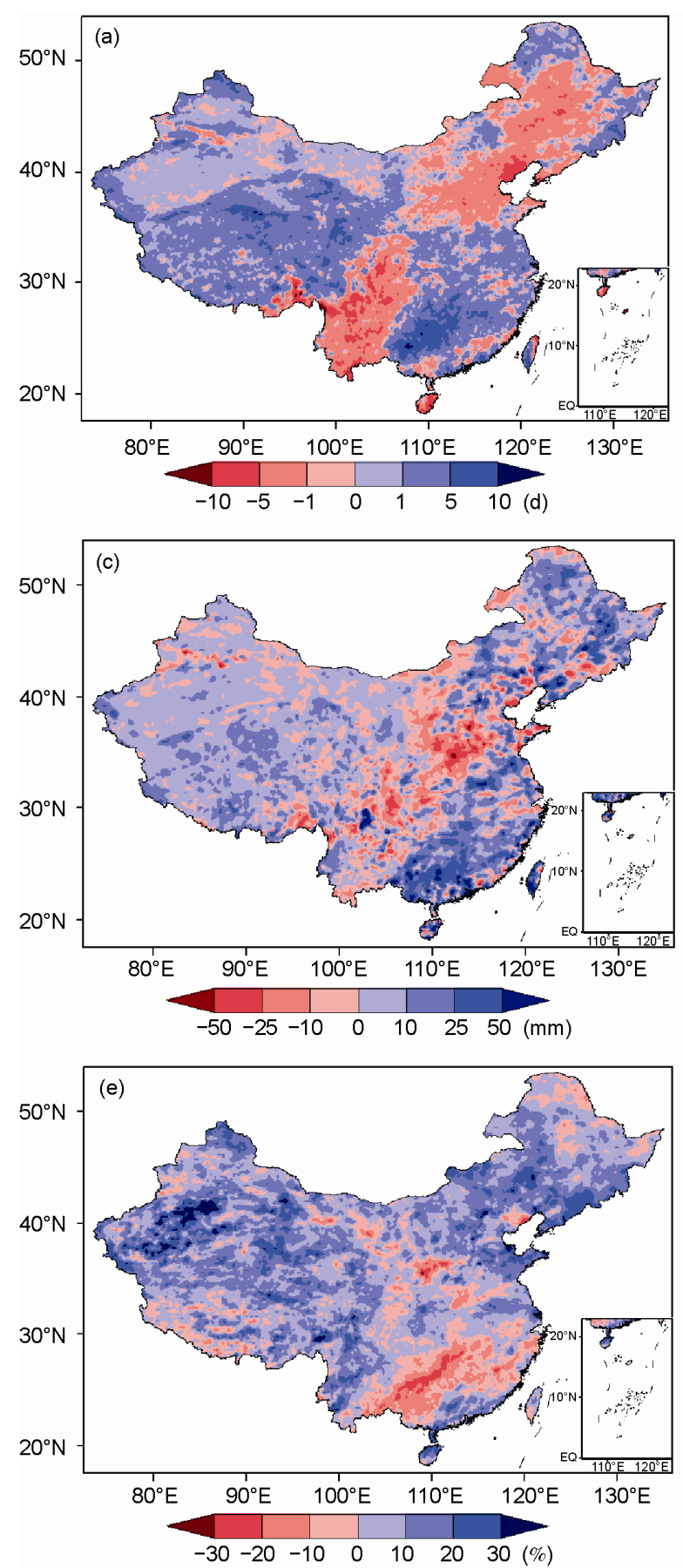

对应着 $2^{\circ} \mathrm{C}$ 全球变暖，中国地区极端降水事件也 发生了很大变化(图 5). 具体而言, 大雨日数在约 $105^{\circ} \mathrm{E}$ 以西地区、东北北部和东部、华南和江淮流域 下游地区增加，而在西南大部、华北和东北中部和南 部地区减少，整个区域大雨日数平均增加 $0.4 \mathrm{~d}$. 持 续干期在大尺度上主要表现为大约以 $35^{\circ} \mathrm{N}$ 为分界线, 在其北侧大部分地区持续干期减小，而其南部地区
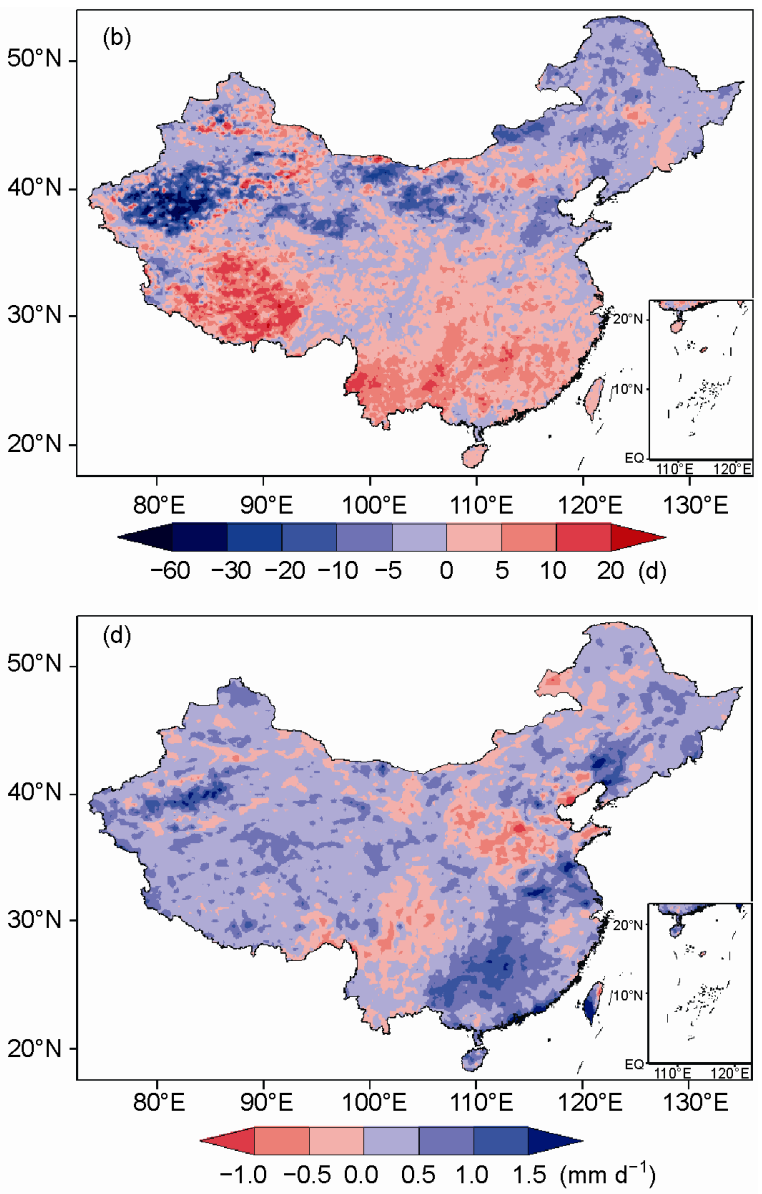

图 5 相对于 1986 2005 年当代气候, 在 2025 2033 年 $2{ }^{\circ} \mathrm{C}$ 全球变暖情景下中国年平均极端降水指标变化

(a) 大雨日数; (b) 持续干期; (c) 连续 5 天最大降水量; (d) 降水强度; (e) 极端降水贡献率 
则以增加为主; 其中, 在塔里木盆地大部分地区减少 20 60 d, 在西藏中部和东部以及华南一部分地区增 加 $5 \mathrm{~d}$ 以上, 而在其余地区变化大多在-20 5 d 以内, 中国区域平均减少 $0.5 \mathrm{~d}$. 连续 5 天最大降水量除在 黄淮以及西南部分地区减少之外, 在中国大部分地 区均以增加为主, 整个区域的平均增加值为 $5.1 \mathrm{~mm}$, 其中在华南和东北一部分地区增加 $10 \mathrm{~mm}$ 以上. 降 水强度除了在西南和黄河下游局部地区略有减小之 外, 在中国其余地区均以增加为主, 主要的高值区位 于华南和长江下游地区以及东北南部局部地区和塔 里木盆地局部地区, 多在 1.0 1.5 $\mathrm{mm} \mathrm{d}^{-1}$ 之间, 中国 区域平均增加 $0.28 \mathrm{~mm} \mathrm{~d}^{-1}$, 这意味着每次降水的平 均强度在增加. 另一方面, 极端降水贡献率在华南一 部分地区减少，而在中国其余大部分地区均以增加 为主, 整个区域的平均增加值为 $6.6 \%$, 这说明未来 强降水事件对总降水的贡献会加大.

\section{3 结论}

根据区域气候模式(RegCM3)在 SRES A1B 温室 气体排放情景下对东亚地区进行的 $25 \mathrm{~km}$ 水平分辨 率的 1948 2100 年连续积分试验数据, 本文首先用与 之嵌套的全球气候模式 MIROC3.2_hires 确定了相对 于工业化革命前期全球变暖 $2^{\circ} \mathrm{C}$ 阈值发生的时间, 而后使用该时段内 $\operatorname{RegCM} 3$ 结果综合研究了在 $2^{\circ} \mathrm{C}$ 全 球变暖情景下, 中国地区年和季节平均气候以及 10 种极端温度和降水事件相对于 1986 2005 年气候态 的变化趋势. 对应着 $2^{\circ} \mathrm{C}$ 全球变暖, 所得主要预估结 果有:

（1）中国年和季节平均温度普遍上升, 年平均变
暖要大于同期全球平均值约 $0.6^{\circ} \mathrm{C}$. 年平均温度升幅 总体上从南向北加强, 青藏高原增暖略大于周边地 区，各季节温度变化间存在着一定的分布差异。

（2）相对于 1986 2005 年，中国年降水平均增加 $5.2 \%$, 在大尺度上主要表现为在中国西部和东南部 地区增加而在两者之间减少. 各季节降水均为增加 趋势, 冬季降水在北方增加而在南方减少, 其他季节 降水变化分布与年平均情况相似.

(3) 东亚夏季风在约 $30^{\circ} \mathrm{N}$ 以北地区略有减弱, 而在其以南地区加强, 东亚冬季风仅在约 $35^{\circ} \mathrm{N}$ 以北 地区减弱, 它们主要源于海陆之间热力和气压差异 变化以及周边大尺度大气环流变化.

(4) 就中国区域平均而言, 年平均霜冻日数减少 $17.0 \mathrm{~d}$, 温度年较差减小 $0.5^{\circ} \mathrm{C}$, 生长季长度增加 18.1 $\mathrm{d}$, 热浪指数增加 $2.1 \mathrm{~d}$, 暖夜指数增加 $19.2 \%$, 大雨 日数增加 $0.4 \mathrm{~d}$, 持续干期减少 $0.5 \mathrm{~d}$, 连续 5 天最大降 水量增加 $5.1 \mathrm{~mm}$, 降水强度增加 $0.28 \mathrm{~mm} \mathrm{~d}^{-1}$, 极端 降水贡献率增加 $6.6 \%$, 这些极端温度和降水事件变 化存在着不同程度的空间变率.

如前所述, 全球变暖 $2^{\circ} \mathrm{C}$ 阈值已经成为国际上有 关气候变化谈判和制定温室气体减排目标的主要依 据. 尽管还存有争议, 但从科学评估和应对气候变化 的角度出发，中国学者现阶段亟需利用本文所得的 高分辨率气候变化情景进一步开展气候变化的影响 和脆弱性研究, 特别是应用于气候变化对农业、水 文、表层生态系统的影响评估 ${ }^{[34,35]}$, 以便从宏观上认 识所谓的 $2{ }^{\circ} \mathrm{C}$ 阈值对中国气候和环境究竟意味着什 么, 从而为国家制定相关气候变化决策或政策提供 翔实数据支撑.

\section{参考文献}

1 IPCC. Climate change 2007: The physical science basis. In: Solomon S, Qin D, Manning M, et al., eds. Contribution of Working Group I to the Fourth Assessment Report of the Intergovernmental Panel on Climate Change. Cambridge, United Kingdom and New York: Cambridge University Press, 2007. 1-996

2 Ding Y H, Ren G Y, Zhao Z C, et al. Detection, causes and projection of climate change over China: An overview of recent progress. Adv Atmos Sci, 2007, 24: 954-971

3 Schneider S H, Semenov S, Patwardhan A, et al. Assessing key vulnerabilities and the risk from climate change. In: Parry M L, Canziani O F, Palutikof J P, et al., eds. Climate Change 2007: Impacts, Adaptation and Vulnerability. Contribution of Working Group II to the Fourth Assessment Report of the Intergovernmental Panel on Climate Change. Cambridge: Cambridge University Press, 2007. 779-810 
4 Meinshausen M, Meinshausen N, Hare W, et al. Greenhouse-gas emission targets for limiting global warming to $2^{\circ} \mathrm{C}$. Nature, 2009 , 458 : 1158-1163

5 Fischlin A, Midgley G F, Price J T, et al. Ecosystems, their properties, goods, and services. In: Parry M L, Canziani O F, Palutikof J P, et al., eds. Climate Change 2007: Impacts, Adaptation and Vulnerability. Contribution of Working Group II to the Fourth Assessment Report of the Intergovernmental Panel on Climate Change. Cambridge: Cambridge University Press, 2007. 211-272

6 丁仲礼, 段晓男, 葛全胜, 等. 2050 年大气 $\mathrm{CO}_{2}$ 浓度控制：各国排放权计算. 中国科学 D 辑：地球科学, 2009, 39: 1009-1027

7 Gleick P H, Adams R M, Amasino R M, et al. Climate change and the integrity of science. Science, 2010, 328: 689-690

8 Guivarch C, Hallegatte S. Existing infrastructure and the $2^{\circ} \mathrm{C}$ target. Clim Change, 2011, 109: 801-805

9 Rogelj J, Hare W, Lowe J, et al. Emission pathways consistent with a $2^{\circ} \mathrm{C}$ global temperature limit. Nat Clim Chang, 2011, 1: 413-418

10 van Vuuren D P, Stehfest E, den Elzen M G J, et al. RCP2.6: Exploring the possibility to keep global mean temperature increase below $2^{\circ} \mathrm{C}$. Clim Change, 2011, 109: 95-116

11 Joshi M, Hawkins E, Sutton R, et al. Projections of when temperature change will exceed $2^{\circ} \mathrm{C}$ above pre-industrial levels. Nat Clim Change, 2011, 1: 407-412

12 Kaplan J O, New M. Arctic climate change with a $2^{\circ} \mathrm{C}$ global warming: Timing, climate patterns and vegetation change. Clim Change, 2006, 79: 213-241

13 Giannakopoulos C, Le Sager P, Bindi M, et al. Climatic changes and associated impacts in the Mediterranean resulting from a $2{ }^{\circ} \mathrm{C}$ global warming. Glob Planet Change, 2009, 68: 209-224

14 May W. The sensitivity of the Indian summer monsoon to a global warming of $2^{\circ} \mathrm{C}$ with respect to pre-industrial times. Clim Dyn, 2011 , 37: $1843-1868$

15 May W. Assessing the strength of regional changes in near-surface climate associated with a global warming of $2{ }^{\circ} \mathrm{C}$. Clim Change, 2012 , 110: 619-644

16 Anderson B T. Intensification of seasonal extremes given a $2^{\circ} \mathrm{C}$ global warming target. Clim Change, 2012, 112: 325-337

$17 \mathrm{Xu} \mathrm{Y,} \mathrm{Xu} \mathrm{C} \mathrm{H,} \mathrm{Gao} \mathrm{X} \mathrm{J,} \mathrm{et} \mathrm{al.} \mathrm{Projected} \mathrm{changes} \mathrm{in} \mathrm{temperature} \mathrm{and} \mathrm{precipitation} \mathrm{extremes} \mathrm{over} \mathrm{the} \mathrm{Yangtze} \mathrm{River} \mathrm{Basin} \mathrm{of} \mathrm{China} \mathrm{in} \mathrm{the}$ 21st century. Quat Int, 2009, 208: 44-52

18 Wang H J, Sun J Q, Chen H P, et al. Extreme climate in China: Facts, simulation and projection. Meteorol Z, 2012, 21: 279-304

19 姜大膀, 张颖, 孙建奇. 中国地区 $1 \sim 3{ }^{\circ} \mathrm{C}$ 变暖的集合预估分析. 科学通报, 2009, 54: 3870-3877

20 姜大膀, 富元海. $2^{\circ} \mathrm{C}$ 全球变暖背景下中国未来气候变化预估. 大气科学, 2012, 36: 234-246

21 Gao X J, Xu Y, Zhao Z C, et al. On the role of resolution and topography in the simulation of East Asia precipitation. Theor Appl Climatol, 2006, 86: 173-185

22 Ju L X, Wang H J, Jiang D. Simulation of the Last Glacial Maximum climate over East Asia with a regional climate model nested in a general circulation model. Palaeogeogr Palaeoclimatol Palaeoecol, 2007, 248: 376-390

23 Zhang D F, Gao X J, Ouyang L C. Simulation of present climate over East Asia by a regional climate model. J Trop Meteorol, 2008, 14: 19-23

24 Gao X, Shi Y, Song R, et al. Reduction of future monsoon precipitation over China: Comparison between a high resolution RCM simulation and the driving GCM. Meteorol Atmos Phys, 2008, 100: 73-86

25 Yu E T, Wang H J, Sun J Q. A quick report on a dynamical downscaling simulation over China using the nested model. Atmos Oceanic Sci Lett, 2010, 3: 325-329

26 Pal J S, Giorgi F, Bi X Q, et al. Regional climate modeling for the developing world: The ICTP RegCM3 and RegCNET. Bull Amer Meteorol Soc, 2007, 88: 1395-1409

27 Shi Y, Gao X J, Zhang D F, et al. Climate change over the Yarlung Zangbo-Brahmaputra River Basin in the 21st century as simulated by a high resolution regional climate model. Quat Int, 244: 159-168

28 高学杰, 石英, 张冬峰, 等. RegCM3 对 21 世纪中国区域气候变化的高分辨率模拟. 科学通报, 2012, 57: 374-381

29 Gao X J, Shi Y, Zhang D F, et al. Uncertainties in monsoon precipitation projections over China: Results from two high-resolution RCM simulations. Clim Res, 2012, 52: 213-226

30 许崇海, 沈新勇, 徐影. IPCC AR4 模式对东亚地区气候模拟能力的分析. 气候变化研究进展, 2007,3: 287-292

31 Sui Y, Lang X. Monsoon change in East Asia in the 21st century: Resutls of RegCM3. Atmos Oceanic Sci Lett, 2012, 5: 504-508

32 Frich P, Alexander L V, Della-Marta P, et al. Observed coherent changes in climatic extremes during the second half of the twentieth century. Clim Res, 2002, 19: 193-212

33 任国玉，封国林，严中伟。中国极端气候变化观测研究回顾与展望. 气候与环境研究, 2010,15: 337-353

34 Chavas D R, Izaurralde R C, Thomson A M, et al. Long-term climate change impacts on agricultural productivity in eastern China. Agric For Meteorol, 2009, 149: 1118-1128

35 Xu H M, Taylor R G, Kingston D G, et al. Hydrological modeling of River Xiangxi using SWAT2005: A comparison of model parameterizations using station and gridded meteorological observations. Quat Int, 2010, 226: 54-59 